\title{
Pesquisa de estrógeno e progesterona no epitélio das pregas vocais de mulheres por imunohistoquímica
}

\author{
Comentado por: Enio Lopes Mello ${ }^{1}$, Marta Assumpção de Andrada e Silva ${ }^{2}$
}

Rios OAB, Duprat AC, Santos AR. Pesquisa de estrógeno e progesterona no epitélio das pregas vocais de mulheres por imunohistoquímica. Rev Bras Otorrinolaringol. 2008;74(4):487-93.

$\mathrm{O}$ artigo sobre a investigação da presença de receptores de estrógeno e progesterona nas pregas vocais de mulheres pode elucidar varias questões sobre a influência da variação hormonal na qualidade vocal.

Fonoaudiólogos, otorrinolaringologistas e alguns profissionais da voz sabem que, durante o período menstrual, ocorrem alterações na qualidade vocal, seja falada ou cantada, devido à variação hormonal. Muitas vezes, recomenda-se aos profissionais da voz, principalmente cantoras, que amenizem os esforços ou cancelem apresentações, durante esse período. No entanto, até o presente momento, não havia sido descrita na literatura médica a ação de receptores hormonais nas pregas vocais ou outros dados, que justificassem as ocorrências de afecções de laringe e disfonias decorrentes da variação hormonal.

Partimos da compreensão de que os hormônios são substâncias químicas que controlam o desenvolvimento, crescimento, auxiliam na reprodução e regulam o metabolismo. Eles são secretados por glândulas ou tecidos especializados, conforme as necessidades do organismo. Os hormônios esteróides (sexuais), por exemplo, são secretados pelos ovários, testículos e glândulas supra-renais e lançados na corrente sanguínea. Geralmente os efeitos biológicos, decorrentes de hormônios, são observados em locais distantes dos sítios de produção. Os hormônios trafegam pelo sangue até atingirem os tecidos alvos e ativam uma série de alterações químicas. Porém, para que isso ocorra são necessários receptores. Normalmente, hormônios lipossolúveis (esteróides) passam através da membrana da célula e se ligam a receptores encontrados no citoplasma. Quando isso ocorre, as moléculas de ambos passam por alterações estruturais, que ativam mecanismos no interior da célula e produzem efeitos específicos decorrentes dos hormônios.

Receptores presentes na superfície das membranas das células são constantemente renovados e os que reagem com

(1) Pós-graduando (Doutorado) em Fonoaudiologia pelo Programa de Estudos Pós-graduados em Fonoaudiologia da Pontifícia Universidade Católica de São Paulo - PUC-SP - São Paulo (SP), Brasil.

(2) Doutora, Professora do Curso de Fonoaudiologia e do Programa de Estudos Pós-graduados em Fonoaudiologia da Pontifícia Universidade Católica de São Paulo - PUC-SP - São Paulo (SP), Brasil; Professora Adjunto do Curso de Fonoaudiologia da Faculdade de Ciências Médicas da Santa Casa de São Paulo - FCMSCSP - São Paulo (SP), Brasil.

Endereço para correspondência: Enio Lopes Mello. R. Dr. Alberto Seabra, 555, casa 04, Vila Madalena, São Paulo (SP), Brasil. CEP: 05452-000. E-mail: enio.mello@ superig.com.br hormônios são decompostos quimicamente ou reciclados. Desta forma, novos receptores são produzidos e inseridos na parede celular. As células podem responder, se necessário, a concentrações anormais de hormônios no sangue. Se houver aumento da concentração de um hormônio no sangue, o número de receptores na parede celular pode diminuir e, com isso, manter o mesmo nível de interação hormonal na célula. Se a concentração hormonal no sangue diminuir, esse mecanismo regulador pode aumentar o número de receptores na célula.

Os autores desse artigo observaram que, embora as funções dos receptores de hormônio sejam de grande importância para a regulação do metabolismo, não há descrição da presença de receptores nos tecidos ósseos, cérebro, mama, testículos, ovários, coração, glândulas lacrimais e pregas vocais, entre outros. Eles apresentaram dois estudos citológicos ${ }^{(1-2)}$ que foram essenciais para as pesquisas dos receptores nas pregas vocais, porque evidenciou-se nesses estudos, que as alterações provocadas por hormônios nas pregas vocais durante o ciclo menstrual, são as mesmas que ocorrem na mucosa do colo uterino. Apresentaram também, dois outros estudos ${ }^{(3-4)}$ que investigaram a presença de receptores de progesterona, estrógeno e testosterona nas pregas vocais. Porém, os resultados para a presença de receptores hormonais foram incongruentes porque, respectivamente, os estudos trabalharam com pacientes com câncer e com idade pós-menopausa. Nesses casos, pode ocorrer uma diminuição da atividade de progesterona. Portanto, deduziu-se que, em ambos os estudos, os receptores não foram localizados ou perderam a função.

A casuística do presente estudo formou-se de 19 amostras de epitélio de pregas vocais de pacientes submetidos à cirurgia, no Departamento de Otorrinolaringologia da Faculdade de Ciências Médicas da Santa Casa de São Paulo, no período de janeiro a dezembro de 1999, com variação de 25 a 34 anos, média de 31,58 anos.

Os resultados não revelaram a presença de receptores de estrógeno no epitélio das pregas vocais, no citoplasma e nem no núcleo celular. Em contrapartida, a presença de receptores de progesterona foi positiva em 18 dos 19 casos estudados. $\mathrm{O}$ único caso em que não houve positividade foi o proveniente de brida das pregas vocais. Os demais casos: ponte mucosa (um caso), cisto submucoso (13 casos), hemangioma (um caso), brida (um caso) e biópsia de laringe (dois casos), foram positivos para progesterona.

Os pesquisadores encontraram receptores de progesterona 
na camada basal do epitélio. Essa é a região de maior atividade proliferativa das pregas vocais e a presença de receptores de progesterona justifica a intensa atividade produtiva da matriz extracelular.

A progesterona é um hormônio importante na regulação da lubrificação da superfície do epitélio, uma vez que, a saída de água do epitélio está diretamente relacionada à sua presença. Esse dado pode elucidar, por exemplo, porque cantoras com disfonia, durante o período menstrual, relatam aumento da produção e viscosidade do muco e/ou rugosidade da superfície das pregas vocais. A viscosidade do muco laríngeo tem influência direta na vibração das pregas vocais; ela pode diminuir a amplitude de vibração da superfície livre e restringir a área de contato da glote. Desta forma, pode comprometer a movimentação da superfície da prega vocal.

Os achados dessa pesquisa possibilitam, também, compreender alguns casos de hemorragia das pregas vocais de cantoras, provocados por abusos ou excesso de atividades do canto durante o período menstrual. Nesse período, são criados novos capilares, a partir dos microvasos existentes. Esses novos capilares sofrem maturação, remodelação e formam uma nova rede vascular a cada ciclo, que é a chamada proliferação angiogênica. Se houver dilatação exacerbada dos novos capilares durante esse processo pode ocorrer hemorragia.

Os autores do artigo concluíram que os receptores de progesterona estão presentes na camada basal do epitélio das pregas vocais, localizados no núcleo e no citoplasma das células. Os receptores de estrogênio não foram encontrados no epitélio das pregas vocais.

Diante da descoberta da presença de receptores de progesterona na camada basal do epitélio, acreditamos que estamos mais próximos de uma compreensão global das alterações que ocorrem nas pregas vocais, seja na modificação do conteúdo líquido (edema ou ressecamento), alteração no epitélio (escamação ou excesso de secreção), seja na vaso dilatação e nas hemorragias decorrentes da presença do hormônio progesterona.

\section{REFERÊNCIAS}

1. Abitbol J, Brux G, Millot, M, Masson O, Mimoun H, Pau B. Does a hormonal vocal cord cycle exist in women? Study of vocal premenstrual syndrome in voice performers by videostroboscopy-glottography and cytology on 38 women. J Voice. 1989;3(2):157-62.

2. Caruso S, Roccasalva L, Sapienza G, Zappalá M, Nuciforo G, Biondi S. Laryngeal cytological aspects in women with surgically induced menopause who were treated with transdermal estrogen replacement therapy. Fertil Steril. 2000;74(6):1073-9.
3. Piatkowski K, Kruk-Zagajewska A, Thielemann A, Kopczyński Z. [Concentration of estrogen and progesterone receptors in normal and neoplastic tissue in patients with laryngeal neoplasm]. Otolaryngol Pol. 2002;56(4):445-50. Polish.

4. Newman SR, Butler J, Hammond EH, Gray SD. Preliminary report on hormone receptors in the human vocal fold. J Voice. 1998;14(1):72-81. 